\title{
Effect of Methyl Jasmonate on Physical and Chemical Properties of Mango Fruit cv. Nam Dok Mai
}

\author{
Panida Boonyaritthongchai *, Chalida Chimvaree, Mantana Buanong, Apiradee Uthairatanakij \\ and Pongphen Jitareerat
}

Division of Postharvest Technology, King Mongkut's University of Technology Thonburi, Bangkok 10150, Thailand; chalida_tai@hotmail.com (C.C.); mantana.bua@kmutt.ac.th (M.B.); apiradee.uth@kmutt.ac.th (A.U.); pongphen.jit@kmutt.ac.th (P.J.)

* Correspondence: panida.boo@kmutt.ac.th; Tel.: +66-2470-7732

Academic Editors: Varit Srilaong, Mantana Buanong, Chalermchai Wongs-Aree, Sirichai Kanlayanarat and Douglas D. Archbold

Received: 7 December 2015; Accepted: 9 November 2016; Published: 30 December 2016

\begin{abstract}
The effect of methyl jasmonate (MeJA) on anthracnose severity and physical and chemical properties of mango fruit cv. Nam Dok Mai was investigated. The mango fruit were harvested at the mature-green stage and the fruit surface was disinfected with $100 \mathrm{ppm}$ sodium hypochlorite solution. The fruit samples were then fumigated with $30 \mathrm{ppm} \mathrm{MeJA}$ in an enclosed container at $25^{\circ} \mathrm{C}$ for $6 \mathrm{~h}$, and subsequently stored at $13{ }^{\circ} \mathrm{C}$ for 18 days. Non-treated fruit were used as the control. The results showed that MeJA had no effect on anthracnose severity, stem end rot disease and color change. MeJA treatment induced ethylene production and enhanced the accumulation of $\beta$-carotene content throughout the storage period compared with non-treated fruit. This result indicated that MeJA treatment may be used to increase the accumulation of $\beta$-carotene content of mango fruit during storage at low temperature.
\end{abstract}

Keywords: fumigation; mango; methyl jasmonate

\section{Introduction}

Mango (Mangifera indica L.) cv. Nam Dok Mai No. 4 is the most popular cultivar in Thailand with lusciously fragrant, sweet juicy flesh and a golden yellow skin color that attracts consumers. In Thailand, anthracnose and stem-end rot are considered the most serious and destructive diseases of mango. It is considered a major problem limiting the storage and shelf life of mango fruit. Methyl jasmonate (MeJA) is a plant hormone and endogenous signal molecule that has important roles in responses to environmental stresses [1-4]. Postharvest application of methyl jasmonate is a new approach for maintenance of quality of fruit, including induction of plant defense systems to protect from disease. Methyl jasmonate can cause changes in physical appearance, mechanical properties, and the composition of bioactive compounds of fruit [5]. It is an important cellular regulator that is involved in diverse developmental stages including fruit ripening, accumulation of pigments, phenolic compounds, antioxidants, and sugars [6-9], and has increased $\beta$-carotene accumulation in ripening tomato fruit [10]. MeJA treatments have reduced deterioration and the development of chilling injury symptoms in three cultivars of mango, Tommy Atkins, Kent, and Zill [11,12], and other fruit species such as guava (Psidium guajava), loquat (Eriobotrya japonica L.), peach (Prunus persica L.) and pomegranate (Punica granatum) $[13,14]$. Jasmonates also play an integral role in intracellular signal transduction cascades which occur in the inducible defense mechanisms that plants have developed against pathogens and other stresses. The objective of this study was to determine the effects of MeJA on physical and biochemical properties, antioxidant systems, and bioactive compounds and quality changes of Nam Dok Mai No. 4 mango fruit during cold storage. 


\section{Experimental Section}

\subsection{Mango Fruit Preparation}

Mango fruit cv. Nam Dok Mai No. 4 were harvested at commercial maturity from Good Agricultural Practices (GAP) farms. They were transported to the Division of Postharvest and Technology, School of Bioresources Technology, King Mongkut's University of Technology Thonburi, Thailand. Fruit were cleaned with tap water, separated by size and color, the fruit surface disinfected with 100 ppm sodium hypochlorite solution, and dried in air at ambient temperature. The fruits were then randomly divided into two groups. One hundred forty-four mangoes were placed in glass jars containing $1.35 \mathrm{~mL} 30 \mathrm{ppm}$ methyl jasmonate (MeJA) or water (for the control) spotted onto filter paper for $6 \mathrm{~h}$ at $25^{\circ} \mathrm{C}$ in darkness. After treatment, fruit were transferred from the treatment jars into plastic baskets covered with perforated polyethylene film and stored at $13^{\circ} \mathrm{C}$ for 18 days. Three replicates ( 9 fruit per one replicate) of each treatment were used for all analyses. Fruit decay and physical and chemical properties were evaluated every 3 days during storage.

\subsection{Disease Incidence of Anthracnose and Stem End Rot}

The severity of anthracnose disease was assessed by the extent of total decayed area on each fruit surface using a 5-point scale [15], where $0=$ no disease symptoms, $1=1 \%-10 \%$ of the fruit surface, $2=11 \%-20 \%$ of the surface, $3=21 \%-30 \%$ of the surface, $4=31 \%-40 \%$ of the surface, and $5=>40 \%$ of the surface affected by anthracnose disease spots. The severity of stem end rot disease was assessed by the extent of total decayed area on each fruit surface using a 5-point scale, where $0=$ no disease symptoms, $1=1 \%-10 \%$ of the fruit surface, $2=11 \%-20 \%$ of the surface, $3=21 \%-30 \%$ of the surface, $4=31 \%-40 \%$ of the surface, and $5=>40 \%$ of the fruit surface exhibited brown rot from stem end rot disease.

\subsection{Colour Changes}

Skin and pulp color were assessed with a tristimulus color different meter (Minolta CR300) and expressed as $L, a$, and $b$ values. These values were used to calculate hue values. Negative a values indicated green and the higher positive a values indicated red color. Higher positive $b$ values indicated a more yellow color.

\subsection{Extraction, Saponification and HPLC Analysis of $\beta$-Carotene}

All extraction and saponification steps were carried out under yellow or dim lights. A fruit sample was ground in an Oster blender until pulverized. $5 \mathrm{~g}$ of sample was added to a $50 \mathrm{~mL}$ round-bottomed Nalgene centrifuge tube. $10 \mathrm{~mL}$ of cold ethanol was added, and the sample was homogenized with a Polytron homogenizer at medium speed for $3 \mathrm{~min} .8 \mathrm{~mL}$ of hexane was added, and the sample was homogenized for an additional $2 \mathrm{~min}$. The mixture was then centrifuged for $4 \mathrm{~min}$ at $7000 \times g$. The carotenoid-bearing hexane layer was transferred with a Pasteur pipet to a $125 \mathrm{~mL}$ screw-cap Ehrlenmeyer flask. $5 \mathrm{~mL}$ saturated sodium chloride solution was added to the contents of the centrifuge tube, and the contents were stirred gently to homogenize the mixture. An additional $8 \mathrm{~mL}$ of hexane was added, and the mixture was homogenized at low speed with the Polytron for $1 \mathrm{~min}$. The mixture was centrifuged as before, and the hexane layer transferred to the Ehrlenmeyer flask with the first extract.

$15 \mathrm{~mL}$ of $10 \%$ methanolic $\mathrm{KOH}$ was added to the contents of the Ehrlenmeyer flask. The flask was flushed with nitrogen, sealed, and wrapped in aluminum foil to exclude light. The flask was left at room temperature for $16 \mathrm{~h}$ with gentle shaking. The mixture was then transferred to a separatory funnel and washed to remove the $\mathrm{KOH}$, first with $50 \mathrm{~mL}$ of $10 \% \mathrm{NaCl}$ solution and then with deionized water until the rinse had a neutral $\mathrm{pH}$. The $\mathrm{KOH}$ solution was further extracted with an additional $10 \mathrm{~mL}$ hexane. The combined hexane extracts were evaporated under nitrogen just to dryness, then redissolved in methylene chloride and brought to volume with mobile phase (see below). The sample was immediately filtered through a $0.45 \mathrm{~mm}$ filter into an amber analysis vial and sealed. 
The HPLC system consisted of a Hewlett Packard Series 1050 autosampler, Series 1050 pump, and a Series $1040 \mathrm{M}$ diode array detector, operated by HP Chemstation software. A $250 \times 4.6 \mathrm{~mm}$, $5 \mathrm{~mm}$ internal diameter Vydac 201TP54 reversed phase C18 column fitted with biocompatible titanium frits was used for separation, together with a Vydac $4.6 \times 25 \mathrm{~mm}$ high performance guard column filled with the same packing material. The mobile phase consisted of acetonitrile, methanol and methylene chloride $75: 20: 5 \mathrm{v} / \mathrm{v} / \mathrm{v}$, containing $0.1 \%$ butylated hydroxytoluene and $0.05 \%$ triethylamine. The methanol contained $0.05 \mathrm{M}$ ammonium acetate. All reagents were HPLC grade. The flow rate was $1.5 \mathrm{~mL} / \mathrm{min}$. Detection was at $450 \mathrm{~nm}$. Identification and purity of peaks was confirmed by comparing spectra using the computer software.

\subsection{Ethylene Production}

Ethylene production was measured during cold storage at $13^{\circ} \mathrm{C}$. Three fruit from each replication were randomly selected to measure respiration rate. Individual fruit were kept in airtight glass jars fitted with a rubber septum for collecting the gases. After $1 \mathrm{~h}$ incubation of the fruit, the head space gas was withdrawn from container using a syringe and injected into a gas chromatograph (Shimadzu, Kyoto, Japan). $\mathrm{N}_{2}$ was used as the carrier gas. Ethylene was quantified using a flame ionization detector. Ethylene was estimated and expressed as $\mu \mathrm{L} \mathrm{C}_{2} \mathrm{H}_{4} / \mathrm{kg} \cdot \mathrm{h}$.

\subsection{Statistical Analysis}

The experiment was arranged in completely randomized design. All data presented were means of three replicates along with standard errors of means, and mean were compared using $t$-test. Differences at $p \leq 0.05$ and $p \leq 0.01$ were considered significant.

\section{Results and Discussion}

\subsection{Disease Severity}

The symptoms of anthracnose disease on MeJA-treated and control mango fruit were observed during storage at $13{ }^{\circ} \mathrm{C}$ by 3 days. MeJA-treated mango and control fruit showed no significant difference in anthracnose or stem end rot disease severity through the end of storage at 18 days (Figure 1A,B). Treatments with MeJA have been reported to suppress gray mold rot (Botrytis cinerea) on strawberries (Fragaria $\times$ ananassa Duch.) [10], to reduce microbial contamination of fresh cut celery (Apium graveolens) and peppers (Capsicum annum) [16], and to suppress fungal decay in grapefruit (Citrus $\times$ paradisi) [17], in contrast to the present results. These differences may be due to the wide range in genetic makeup of different horticultural crops and different treatment methods with MeJA among studies [18]. MeJA has been shown to prevent postharvest diseases in a number of horticultural crops, but the mode of action in reducing disease has not been well-characterized, although MeJA effects could be because of a direct inhibitory effect on pathogen growth and/or because of the induction of natural disease resistance [17].
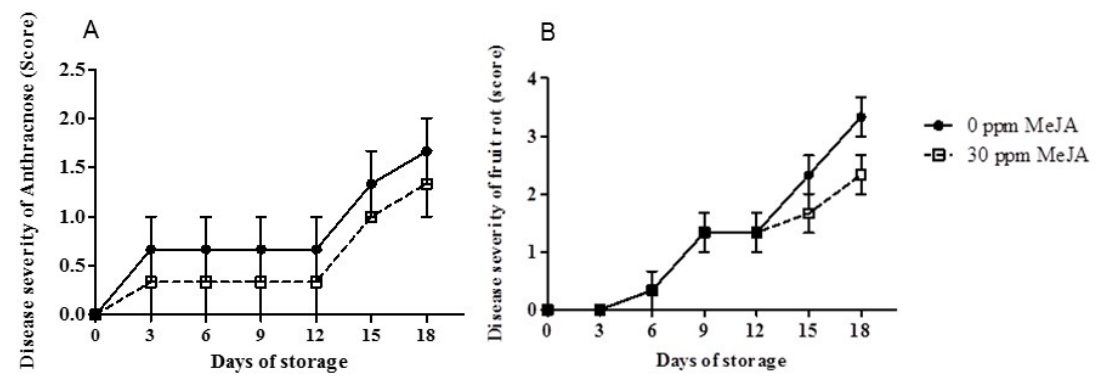

Figure 1. Disease severity of anthracnose (A) and stem end rot (B) in the mango fruit cv. Nam Dok Mai No.4 fumigated with $30 \mathrm{ppm}$ methyl jasmonate (MeJA) versus untreated controls during storage at $13{ }^{\circ} \mathrm{C}$ for 18 days. There was no difference between treated and control fruit on any day. 


\subsection{Internal Pulp Color}

The $\mathrm{L}$ value, or the lightness of the yellow pulp, and $\mathrm{b}$ value, expressing blue $(-)$ to yellow $(+)$ color did not differ between the MeJA treatment and controls on any day (Figure 2A,B). The a value, expressing green $(-)$ to red $(+)$ color, and hue angle were only higher for MeJA treatment at 18 days (Figure $2 \mathrm{C}, \mathrm{D}$ ). Colour change of mango pulp as $\mathrm{L}, \mathrm{a}$, and $\mathrm{b}$ values, and hue angle, was constant through 12 days of storage, but changed between 12 and 18 days. The $L$ value and hue angle value of both treatments decreased, while $\mathrm{a}$ and $\mathrm{b}$ values of both treatments increased. Pulp color of both treatments changed from light yellow to dark yellow after 12 days.
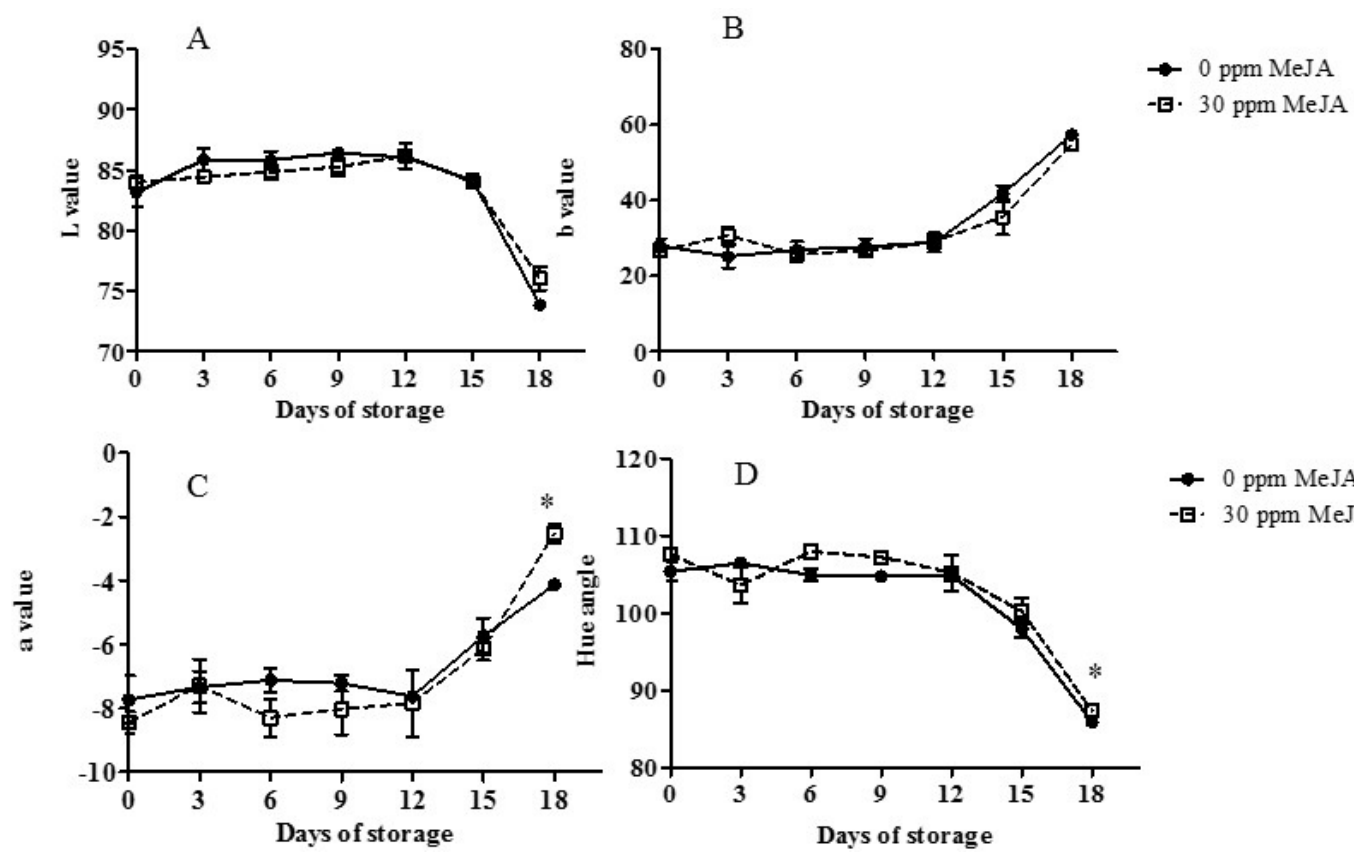

Figure 2. Colour change expressed as $\mathrm{L}(\mathbf{A}), \mathrm{b}(\mathbf{B})$, a (C), and hue angle (D) values of the fruit pulp of cv. Nam Dok Mai No.4 fumigated with 30 ppm methyl jasmonate (MeJA) versus untreated (control) during storage at $13{ }^{\circ} \mathrm{C}$ for 18 days. An asterisk indicates a statistically significant difference at $p \leq 0.05$; otherwise, treatments did not differ.

\subsection{Peel Color}

MeJA treatment showed a higher $L$ value than controls at 3 and 15 days of storage, but a lower value than controls at 18 days (Figure $3 \mathrm{~A}$ ). The $\mathrm{a}$ and $\mathrm{b}$ values and hue angle of both treatments was maintained for 12 days of storage, but $a$ and $b$ values declined from 12 to 18 days while hue angle increased (Figure 3B-D). However, MeJA values did not differ from controls in these traits. The response of mango to MeJA has depended on the maturity stage, cultivar and subsequent storage temperature [19]. Gonzalez-Aguilar et al. [19] reported that use of $10^{-5} \mathrm{M}$ MeJA enhanced yellow and red colour development of mango $\mathrm{cv}$. Kent stored at $20^{\circ} \mathrm{C}$, but in the present research the fruit were kept at a lower temperature $\left(13^{\circ} \mathrm{C}\right)$, so it is possible that the colder storage suppressed color development. 

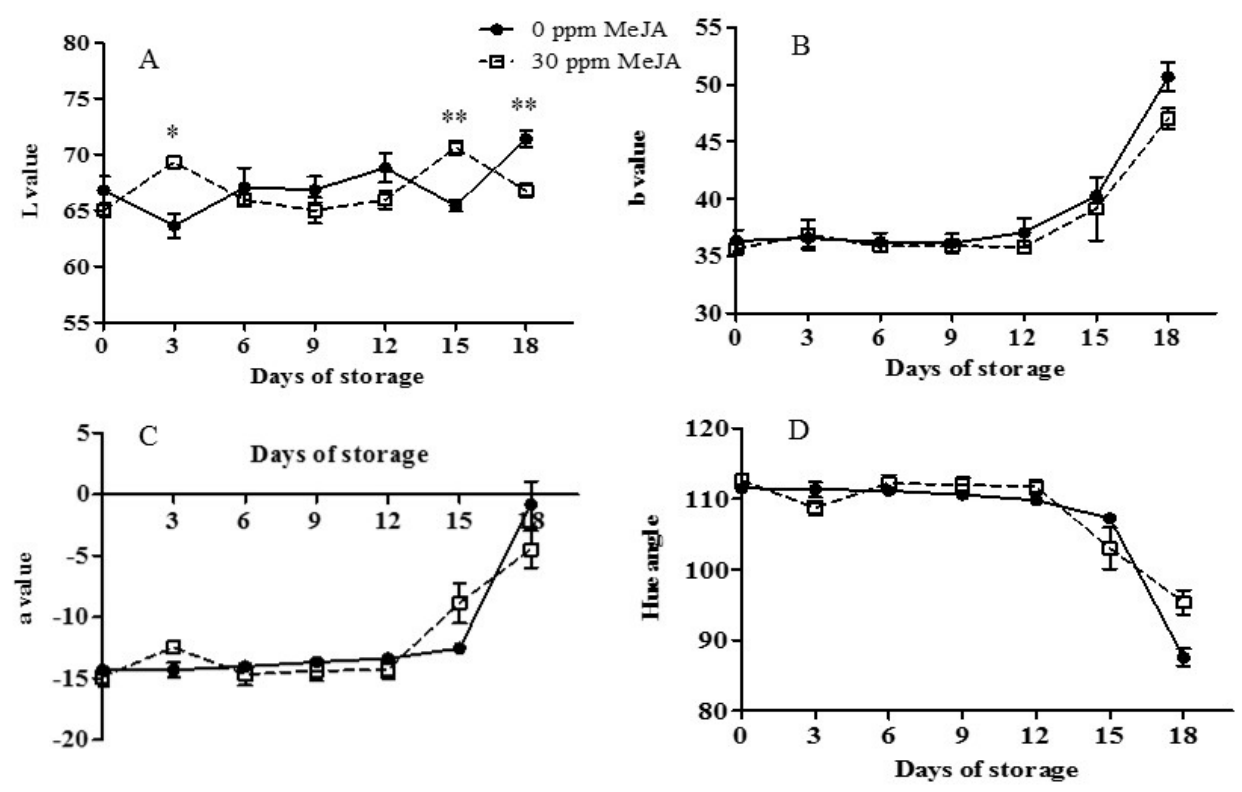

Figure 3. Colour change expressed as L (A), b (B), a (C), and hue angle (D) values of the fruit peel of cv. Nam Dok Mai No.4 fumigated with 30 ppm methyl jasmonate (MeJA) versus untreated (control) during storage at $13{ }^{\circ} \mathrm{C}$ for 18 days. Asterisks indicate a statistically significant difference at $p \leq 0.05\left(^{*}\right)$ or $\left.p \leq 0.01{ }^{* *}\right)$; otherwise, treatments did not differ.

\subsection{Ethylene Production}

MeJA-treated fruit showed a significantly higher ethylene production than control fruit at day 9 of storage, while control fruit showed its highest production at 12 days although it was not higher than MeJA-treated fruit (Figure 4). The ethylene production of MeJA treatment decreased after 9 days until the end of storage. The ethylene production of control fruit increased gradually until reaching a peak at day 12 of storage, and then decreased until the end of storage. MeJA enhanced softening in apple, promoting apple ripening as indicated by increased ethylene biosynthesis, acceleration of yellowing and softening [20]. The present results were similar to the effect of MeJA on ethylene production in tomato fruit [21] and increased ethylene-forming enzyme activity in preclimacteric apple fruit [22].

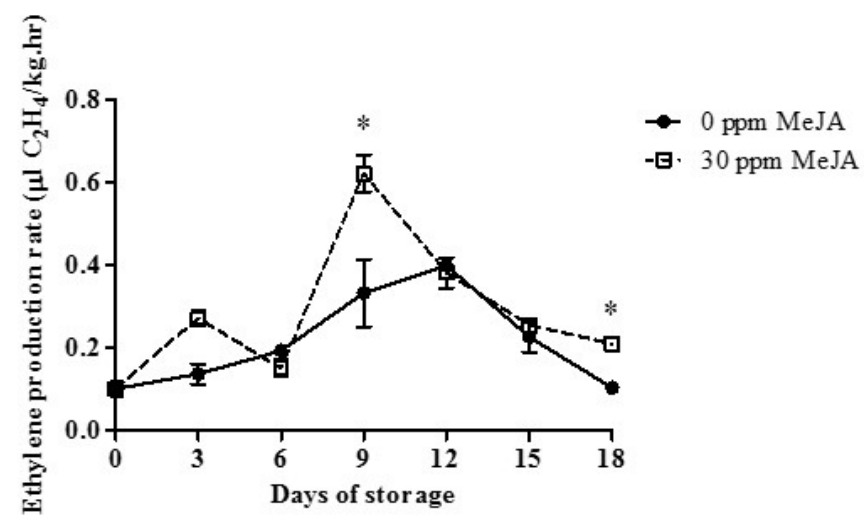

Figure 4. Ethylene production of mango fruit, cv. Nam Dok Mai No.4, fumigated with 30 ppm methyl jasmonate (MeJA) versus untreated (control) during storage at $13{ }^{\circ} \mathrm{C}$ for 18 days. An asterisk indicates a statistically significant difference at $p \leq 0.05$; otherwise, treatments did not differ. 


\section{5. $\beta$-Carotene Content}

$\beta$-Carotene content of mango pulp of MeJA-treated and control fruit increased during storage (Figure 5). MeJA-treated mango showed a significantly higher $\beta$-carotene content than control fruit at 15 and 18 days of cold storage. Application of MeJA vapour improved skin color by promoting $\beta$-carotene synthesis and chlorophyll degradation in Golden Delicious apple [20]. The response of mango fruit to MeJA depends up on the maturity stage, cultivar and subsequent storage temperature [19]. MeJA has been shown to increase $\beta$-carotene accumulation in ripening tomatoes [23].

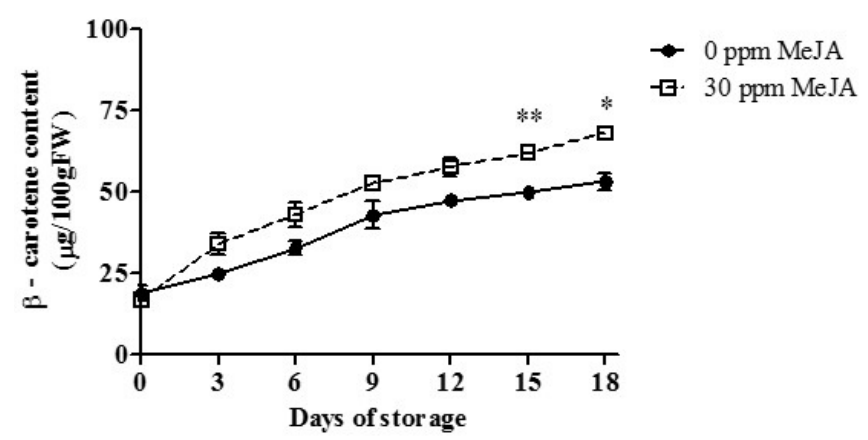

Figure 5. $\beta$-carotene content of mango fruit, cv. Nam Dok Mai No.4, fumigated with $30 \mathrm{ppm}$ methyl jasmonate (MeJA) versus untreated (control) fruit during storage at $13{ }^{\circ} \mathrm{C}$ for 18 days. Asterisks indicate statistically significant differences at $p \leq 0.05\left(^{*}\right)$ and $p \leq 0.01\left(^{* *}\right)$; otherwise, treatments did not differ.

\section{Conclusions}

A 30 ppm MeJA fumigation treatment did not reduce disease severity from anthracnose or stem end rot in mango cv. Nam Dok Mai No. 4 during storage at $13{ }^{\circ} \mathrm{C}$. Nor did the MeJA fumigation treatment have an effect on color change of mango peel, although there was a small effect on pulp color. MeJA treatment increased maximum ethylene production and induced greater accumulation of $\beta$-carotene in mango pulp.

Acknowledgments: We are grateful to the National Research University Project for financial support of this research.

Author Contributions: P.B., M.B., A.U. and P.J. conceived and designed the experiments. M.B., P.B. and C.C. performed the experiments. P.J. and A.U. analyzed the data. P.B. and P.J. drafted and revised it critically for important intellectual content.

Conflicts of Interest: The authors declare no conflict of interest.

\section{References}

1. Raskin, I. Salicylic acid, a new plant hormone. Plant Physiol. 1992, 99, 799-803. [CrossRef] [PubMed]

2. Creelman, R.A.; Mullet, J.E. Biosynthesis and action of jasmonate in plants. Ann. Rev. Plant Physiol. Plant Mol. Biol. 1997, 48, 355-381. [CrossRef] [PubMed]

3. Ananieva, E.A.; Christov, K.N.; Popova, L.P. Exogenous treatment with salicylic acid leads to increased antioxidant capacity in leaves of barley plant sexpose to paraquat. J. Plant Physiol. 2004, 161, 319-328. [CrossRef] [PubMed]

4. Wang, L.; Chen, S.; Kong, W.; Li, S.; Archbold, D.D. Salicylic acid pretreatment alleviates chilling injury and affects the antioxidant system and heat shock protein of peaches during cold storage. Postharvest Biol. Technol. 2006, 41, 244-251. [CrossRef]

5. Fan, X.; Mattheis, J.P.; Fellman, J.K.; Patterson, M.E. Effect of methyl jasmonate on ethylene and volatile production by Summered apples depends on fruit developmental stage. J. Agric. Food Chem. 1997, 45, 208-211. [CrossRef]

6. Cheong, J.J.; Choi, Y.D. Methyl jasmonate as a vital substance in plants. Trends Genet. 2003, 19, 409-413. [CrossRef] 
7. Burhan, O.; Ebubekir, A.; Kenan, Y.; Yakup, O.; Onur, S. Effect of methyl jasmonate treatments on the bioactive compounds and physicochemical quality of "Fuji" apples: Ciencia e InvestigaciÓn Agraria. Crop Prod. 2013, 40, 201-211.

8. Rohwer, C.L.; Erwin, J.E. Horticultural applications of jasmonates: A review. J. Hortic. Sci. Biotechnol. 2008, 83, 283-304. [CrossRef]

9. Heridia, J.B.; Zevallos, C. The effects of exogenous ethylene and methyl jasmonate on the accumulation of phenolic antioxidants in selected whole and wounded fresh produce. Food Chem. 2009, 115, 1500-1508. [CrossRef]

10. Saniewski, M.; Czapski, J. The effect of methyl jasmonate on lycopene and $\beta$-carotene accumulation in ripening red tomatoes. Experientia 1983, 39, 1373-1374. [CrossRef]

11. González-Aguilar, G.A.; Fortiz, J.; Cruz, R.; Baez, R.; Wang, C.Y. Methyl jasmonate reduces chilling injury and maintains postharvest quality of mango fruit. J. Agric. Food Chem. 2000, 48, 515-519. [CrossRef] [PubMed]

12. González-Aguilar, G.A.; Buta, J.G.; Wang, C.Y. Methyl jasmonate and modified atmosphere packaging (MAP) reduce decay and maintain postharvest quality of papaya "Sunrise". Postharvest Biol. Technol. 2003, 28, 361-370. [CrossRef]

13. González-Aguilar, G.A.; Tiznado-Hernández, M.E.; Zavaleta-Gatica, R.; Martínez-Téllez, M.A. Methyl jasmonate treatments reduce chilling injury and activate the defense response of guava fruits. Biochem. Biophs. Res. Commun. 2004, 313, 694-701. [CrossRef]

14. Meng, X.; Han, J.; Wang, Q.; Tian, S. Changes in physiology and quality of peach fruits treated by methyl jasmonate under low temperature stress. Food Chem. 2009, 114, 1028-1035. [CrossRef]

15. Chantrasri, P. Induction of Resistance to Anthracnose Disease of Postharvest Mango Fruit by Antagonist Yeasts. Master's thesis, Chiangmai University, Chiang Mai, Thailand, 2006.

16. Buta, J.G.; Moline, H.E. Methyl jasmonate shelf life and reduces microbial contamination of fresh cut celery and peppers. J. Agric. Food. Chem. 1998, 46, 1253-1256. [CrossRef]

17. Droby, S.; Porat, R.; Cohen, L.; Weiss, B.; Shapira, B.; Philosoph-Hasas, S.; Meir, S. Suppressing green mold decay in grapefruit with postharvest jasmonate application. J. Am. Soc. Hortic. Sci. 1999, 124, 184-188.

18. Wang, K.; Dickinson, R.E.; Liang, S. Clear sky visibility has decreased over land globally from 1973 to 2007. Science 2009, 323, 1468-1470. [CrossRef] [PubMed]

19. Gonzalez Aguilar, G.A.; Buta, J.G.; Wang, C.Y. Methyl jasmonate reduces chilling injury symptoms and enhance color development of "Kent" mangoes. J. Sci. Food Agric. 2001, 81, 1244-1249. [CrossRef]

20. Perez, A.G.; Sanz, C.; Richardson, D.G.; Olias, M. Methyl jasmonate promotes $\beta$-carotene synthesis and chlorophyll degradation in Golden Delicious apple peel. Plant Growth Regul. 1993, 12, 163-167. [CrossRef]

21. Saniewski, M.; Czapski, J. Stimulatory effect of methyl jasmonate on ethylene production in tomato fruits. Experientia 1985, 41, 256-257. [CrossRef]

22. Saniewski, M.; Nowacki, J.; Lange, E.; Czapski, J. The effect of methyl jasmonate on anthocyanin accumulation, ethylene production and ethylene forming enzyme activities in apple. Fruit Sci. Rep. 1988, 15, 97-102.

23. Olias, J.M.; Rios, J.J.; Valle, M.; Zamora, R.; Sanz, L.C.; Axelroad, B.A. Fatty acid hydroperoxide lyase in germinating soybean seedlings. J. Agric. Food Chem. 1990, 38, 624-630. [CrossRef]

(C) 2016 by the authors; licensee MDPI, Basel, Switzerland. This article is an open access article distributed under the terms and conditions of the Creative Commons Attribution (CC-BY) license (http://creativecommons.org/licenses/by/4.0/). 